\title{
The Sense and Pointlessness of the Concept of a Norm in the Analysis of Psychopathic Personality Disorders

\author{
Beata Pastwa-Wojciechowska and Mariola Bidzan*
}

Institute of Psychology, University of Gdańsk, Poland

\begin{abstract}
In this article we are going to use the term 'psychopathy', in contrary to the tendency prevailing to use modern terminology recommended by psychiatric diagnostics guidelines, both DSM (Diagnostic and Statistical Manual of Mental Disorders) and ICD (International Classification of Diseases). We want to show, that the term 'psychopathy' is well operationalized construct, investigated extensively both on theoretical and empirical grounds. This psychologicalpsychiatric term is - like no other - closely related to the violation of norms, especially legal ones.

In the following thesis we would like to discuss the role and significance of norms, including legal ones, in the functioning of individuals with psychopathic personality disorders. Therefore posing a question about the role and significance of norms in etiology and diagnostics of psychopathy seems to be an important issue.

The question if is the concept of a psychopathy of a norm useful in the analysis of psychopathic personality disorders is rhetorical, because it is hard not to include e.g. clinical norms in etiology or diagnostics of the discussed personality type. In addition, as we have already mentioned, psychopathy is featured by breaking or disobeying the binding moral, ethical, legal etc. norms and regulations, which is often reflected by psychopaths' criminal activity. Therefore these individuals have both individual and social disorders.
\end{abstract}

Keywords: Psychopathy; DSM (Diagnostic and Statistical Manual of Mental Disorders); ICD (International Classification of Diseases); Psychopathic personality disorders

\section{Introduction}

In the following thesis we are going to use the term 'psychopathy', in contrary to the tendency prevailing in the Polish reference books to use modern terminology recommended by psychiatric diagnostics guidelines, both DSM (Diagnostic and Statistical Manual of Mental Disorders) and ICD (International Classification of Diseases). The term 'psychopathy' is used in the global literature of the subject as an operationalized construct, investigated extensively both on theoretical and empirical grounds. This psychological-psychiatric term is-like no other-closely related to the violation of norms, especially legal ones. In the following thesis we would like to discuss the role and significance of norms, including legal ones, in the functioning of individuals with psychopathic personality disorders. It is assumed that such persons demonstrate problems with acquiring, and hence respecting, the binding norms and regulation, which is reflected by a high percentage of psychopaths in the population of individuals violating legal norms. In addition, psychopaths exhibit a tendency to violate all kinds of legal norms, not specializing in an certain type of crime, which is described as 'criminal versatility'. Therefore posing a question about the role and significance of norms in etiology and diagnostics of psychopathy seems to be an important issue. The concept of psychopathy. A few remarks about terminology. On the one hand the concept of psychopathy is still one of the most controversial and ambiguous terms in psychiatric-psychopathological literature, and on the other hand it still stimulates scientists and clinicians to further research. Analyzing world literature, clinical and judicial practice reports, it can be noticed that both the DSM and ICD classifications suggest different terminology and diagnostic criteria to determine personality types, which are assumed to be identical (antisocial, asocial, dissocial, sociopathic, incorrect, psychopathic personality). It is worth mentioning that the multiplicity of the applied terminology, and hence the number of diverse clinical diagnoses, increased the number of studies on the unification of terminology on the one hand, an on the other-on differential diagnosis of the aforementioned personality types [1-5]. It is noted that to a large extent the terminological discrepancies result from the distinctiveness of models which describe them. The medical model prefers the taxonomical approach, while the psychological model emphasizes the psychopathology of adaptive and mental regulation mechanisms of a man. However, independent of the model applied to diagnose and analyze psychopathy, it is doubtlessly a clinical construct, relate to personality disorders. Jakubik [6] points out that 'personality disorders have to be defined as relatively permanent and systemic inhibition of personality development', yet we consider them as 'a uniform, holistic clinical category, which does not differentiate separate clinical types'. Such an approach allows defining, whether we deal with personality disorders or not. In case of psychopathy such a division may turn out to be very significant, because a diagnosis of such a type of disorder is not equivalent to a negative assessment of social functioning.

Due to difficulties related to defining a clear border between features of normal persons and psychopaths, some of authors introduce the term of psychopathic personality. In this way they try to define the type of organizational structure of personality, which determines the ways of adaptation or lack of adaptation to the conditions of social life. Such an approach to the discussed personality type is emphasized most

${ }^{*}$ Corresponding author: Mariola Bidzan, Institute of Psychology, University of Gdańsk, Poland, Tel: +48-58-523-24-00; E-mail: mariola.bidzan@ug.edu.pl

Received August 27, 2013; Accepted January 29, 2014; Published February 03 2014

Citation: Wojciechowska BP, Bidzan M (2014) The Sense and Pointlessness of the Concept of a Norm in the Analysis of Psychopathic Personality Disorders. J Socialomics 3: 106. doi:10.4172/2167-0358.1000106

Copyright: (C) 2014 Wojciechowska BP, et al. This is an open-access article distributed under the terms of the Creative Commons Attribution License, which permits unrestricted use, distribution, and reproduction in any medium, provided the original author and source are credited. 
frequently in the reference literature, because disadaptive behaviors comprise a significant element of functioning of psychopaths. Violating all norms-legal, social, moral and ethical-is a constituent of functioning of psychopaths.

Including the concept of psychopathy as a psychopathological unit in diagnostics has drawn attention of a growing number of researchers and clinicians, who emphasize its higher descriptive accuracy and explanatory power. This concept allows to characterize it in terms of psychological dynamics, which prevents psychopathy from being identified with such personality disorders, as antisocial or dissocial personality. This term is used consciously more and more often to refer to children, youth and adults [7]. The development of empirical studies, combined with scientific theories, especially Robert D. Hare's concept, makes psychopathy a construct, which cannot be ignored or treated as nonexistent.

\section{Concepts of psychopathy according to Robert D. Hare}

The first factor describes a constellation of psychopathic features, which many clinicians consider vital for this personality type, i.e. features related to interpersonal, emotional and verbal style of functioning:

1) glibness, superficial charm,

2) grandiose sense of self-worth,

3) proneness to boredom,

4) pathological lying,

5) conning, manipulative,

6) lack of remorse,

7) shallow affection,

8) callous, lack of empathy,

9) parasitic lifestyle,

10) poor behavioral controls

11) promiscuous sexual behavior,

12) early behavioral problems,

13) lack of realistic, long term goals,

14) impulsivity,

15) irresponsibility,

16) failure to accept responsibility,

17) many short-term marital relationships,

18) juvenile delinquency,

19) revocation of conditional release,

20) criminal versatility

The reference literature uses the term 'psychopathy' more and more often. It is frequently identified with the operational definition of psychopathy by Hare $[2,8]$ and with the diagnostic method called 'The Psychopathy Checklist-Revision (PCL-R)'. The operational definition has one definite advantage-it allows both to differentiate precise diagnostic criteria, and to develop a tool used to measure them, which made it very popular among scientists and practitioners. The criteria suggested by Hare $[1,8]$ enable the measurement of two factors, each of them described by 10 items. The first factor describes a constellation of psychopathic features, which many clinicians consider vital for this personality type, i.e. features related to interpersonal, emotional and verbal style of functioning: [1) Glibness, superficial personal charm, 2) Exaggerated self-esteem, 3) Enhanced need of stimulation combined with increased susceptibility to boredom, 4) Pathological mendacity, 5) Tendency to lead by manipulation, 6) Lack of remorse or feeling of guilt, 7) Superficial emotionality, 8) Lack of sensitivity or empathy, 9) Parasitic existence, 10) Weak control of behavior]. This factor correlates positively with clinical determiners of psychopathy, especially with narcissistic and histrionic personality disorders and measures of Machiavellianism. It correlates negatively with measures of empathy and anxiety. Meanwhile, the second factor describes behaviors indicating impulsiveness, lack of stability and antisocial lifestyle [11) Numerous sexual contacts, 12) Early educational problems, 13) Lack of realistic, long-term goals, 14) Impulsiveness, 15) Irresponsibility, carefreeness, 16) Lack of responsibility for the undertaken actions, 17) Numerous, short-term relationships, 18) Committing a crime as a minor, 19) Repeal of parole, 20) Criminal versatility]. Variables contained in this factor correlate with the criteria of antisocial personality disorders $[2,8]$.

As we can see, the concept of psychopathy correlates strongly with the concept of a norm, or rather with the violation of a norm. The point is that normality and abnormality of psychopaths' behavior is first of all referred to the normative order, and secondly-to the social norms. It has to be emphasized that a legal norm consists of three elements-a hypothesis, a disposition and a reaction. Each of these elements has a different role, also in terms of psychology. A hypothesis specifies conditions, under which the norm addressee is made, allowed or forbidden to do something, i.e. knowledge on what he can or must not do is provided to him. Meanwhile, a disposition specifies the kind of desired or allowed behavior, and reaction determines the degree of severity of a punishment for violating a norm (disposition). In other words, we can reason about a certain process, but not its separate elements. However, independent of the norm obedience issue, we expect a man to obey norms at the behavioral level, and hence there will be no need to impose sanctions.

Therefore, analyzing the relation between psychopathy and the concept of a norm, we have to differentiate disorders related to any of the phases of a legal norm, from disorders related to learning all kinds of norms, including legal ones, and from disorders related to learning the consequences of violating legal norms. Before we answer the above questions, we would like to point out that the image of psychopathy is not homogenous in terms of gender, which has a significant impact on obeying or disobeying the norms. In other words, we have to ask a question, whether the gender factor can affect acquiring and respecting norms.

The first factor analyzed during criminological studies is the percentage rate of psychopathic individuals in the criminal population. As it can be concluded from M. Grann's studies (2000) on a population of individuals, who violated legal norms, psychopathy is more often diagnosed among men (31\%) than women (11\%), which means that mean achieve a higher overall result in the PCL-R test more often, than women. In addition, analyzing the factor structure of psychopathy in terms of gender, it turned out that in case of factors 1 (interpersonalemotional) and 2 (behavioral), men achieve higher results than women, nevertheless these differences were statistically not significant. Men achieve the maximum result ( 2 points) more often in position 7 (superficial emotionality), 8 (lack of sensitivity or empathy), 14 (impulsiveness), 18 (committing a crime as a minor) and 20 (criminal versatility). Meanwhile women achieved the maximum result more often in position 11 (numerous sexual contacts) and 15 (impulsiveness). According to Grann, it is significant that men are featured by such variables, as lack of sensitivity, empathy and committing a crime as a minor, while women are characterized by promiscuity. 
Also Salekin et al. [9], who conducted research on validating PCL-R, noticed that psychopathy is less frequent among women, than men. Only $15 \%$ of women violating legal norms and diagnosed using the PCL-R test turned out to be psychopathic. Women are also featured by lower intensity of antisocial behaviors, nevertheless they are the same, as in men, e.g. weak control of behavior (position 10), lack of realistic goals (position 13), impulsiveness (position 14), lack of responsibility for the undertaken actions (position 16), numerous, short-term relationships (position 17), repeal of parole (position 19). What seems interesting, factor 1 is explained especially by the following variables: lack of empathy or feeling of guilt, mendacity, susceptibility to boredom, enhanced need of stimulation. Factor 2 is explained especially by the following variables: early educational problems, promiscuity, exhibiting antisocial behaviors in adult life. Summing up the obtained study results, the authors claim that further research should be undertaken on the relation between the diagnosis of psychopathy, gender, and coexistence of antisocial behaviors. Results concerning juvenile girls and boys with psychopathic personality structure are very interesting. According to the studies conducted by Schmidt et al. [10] using PCL-R:YV (The Psychopathy Checklist-Revision: Youth Version), there are no statistically significant differences between boys and girls in the overall test result. However, only in case of boys there was a relation between psychopathy and the measures of recurrent criminal behavior and the use of violence. Nonetheless, most studies using PCL:YV were conducted on a population of boys, and only some of them included small groups of girls, which did not allow to analyze potential gender differences. It can be only assumed that the factor related to socialization of women delays the recognition and diagnosis of antisocial behaviors, or the different structure of female behaviors makes them more difficult to analyze in terms of legal norms. Meanwhile, comparative studies of girls and women with diagnosed psychopathy, focused mostly on the analysis of antisocial behaviors [11].

What is worth emphasizing, the number of girls and women who violate the law is growing, therefore investigating the significance of psychopathy in terms of violating legal norms by women seems very important. In contrary to men, women with diagnosed psychopathy take a different approach in order to achieve the same goals [5].

Meanwhile, analyzing empirical reports of other authors about gender differences among individuals with psychopathic personality structure, the following tendencies can be observed: a) an increase in the number of diagnosed psychopathic personality disorders, both with women and men, nonetheless the latter prevail; b) women with psychopathic personality disorders exhibit fewer symptoms of this disorder than men [9], but they demonstrate a higher indicator of suicidal tendencies [12]. It is worth mentioning that although many researchers emphasize strongly the existence of gender differences in personality image among individuals with psychopathic personality structure, we do not have reliable empirical and clinical research results concerning this matter [12,5]. Investigating the symptoms of social maladjustment among women, it was observed that they get divorced, are unemployed and become dependent on welfare more often [12]. According to studies conducted by Lilienfeld et al. [13] and Frick [14], women, compared to men, develop behavioral problems later (between 14-16 years of age), undertake sexual contacts more often, exhibit fewer aggressive behaviors and at a later age, and suffer from somatization disorders more frequently and intensely. In other words, the socialization process of women results in the fact that we observe fewer symptoms of behaviors with them, which are considered to be asocial, including aggression. The result confirming a higher number of somatization disorders and greater promiscuity among women is more controversial It could mean that women who were brought up in a family with a dominant and authoritarian father with psychopathic personality structure, and could be sexually abused, may develop somatizations and undertake numerous sexual contacts. Paradoxically, by sexualizing their behavior, women could pursue acceptance and seek love.

\section{Psychopathy and the process of learning}

The concept of learning plays an important role in explaining and describing personality disorders, where this term is used to refer to a process, which leads to relatively permanent modifications of an individual's behavior, due to his previous experience. Therefore underdevelopment of the learning ability, which is a symptom of personality disorders, is demonstrated by e.g. the lack of ability to solve problems, and hence deteriorates the problematic thinking skills.

However, first of all we would like to note that the concept of psychopathy in terms of the learning theory was described in the Polish reference literature by such classic authors, as Ciarkowska [15]. The knowledge about the learning process of psychopaths, especially emotional one, seems to be important according to Ciarkowska [15] for the following reasons: a) psychopathy may be considered as a result of the inability to learn appropriate behavioral norms, required to function correctly on social grounds; b) psychopathy may be considered as actions aimed at eliminating or modifying certain behaviors based on general learning regularities; c) empirical studies on psychopaths' learning are an example of applying the experimental verification scheme for hypotheses formulated on the basis of clinical observations.

Therefore, referring to the presented division, we would like to present in more detail first of all the stream of research referring to the social functioning disorders of psychopaths. Psychopathic personality disorders are most often analyzed in terms of behavior's compliance with various regulation standards, e.g. needs, social or legal norms, possessed experience $[1,2,4,5,16]$. However, we have to bear in mind that when looking for sensations (stimulation), psychopaths tend to violate all norms and rules. These individuals have problems with monitoring their own emotional states and actions. They demonstrate impulsiveness, inability to plan, irritability, aggressiveness, carefreeness, neglecting their own and the others' safety. In addition they lack responsibility, remorse and are completely indifferent to harm done to other people. They neglect taking care of their child or children, leave workplace without any reason. Their social behavior is featured by rivalry, lack of trust; morality is treated as an illusion, kindness means weakness, and trustnaivety. They most often lie and manipulate for pleasure or personal profit, while their motivation for such behaviors may vary, resulting both from their desire for power, and sexual motives. Impulsiveness is demonstrated by the inability to plan, because psychopaths take decisions on the spot, not worrying about the consequences of their actions. Instead of solving problems, they prefer to take revenge for harm which they actually caused. A characteristic feature of this personality type is emotional coldness, which is equivalent to not experiencing such emotions, as compassion or feeling of guilt. Such individuals cannot understand the suffering of other people, which is why they find it so easy to torment others psychologically and physically. Some psychopaths are able to mask their lack of scruples and empathy, maintaining verbal communication skillfully. They also do not tolerate frustration and meanwhile barely experience 
anxiety, which means that punishment and anxiety are not factors inhibiting their behavior $[1,4,5]$.

It is worth noticing that contemporary studies on psychopaths' learning refer mostly to the problem of emotions [4,7]. Analyzing the problem of emotions with psychopaths, two aspects have to be differentiated: experiencing emotions and controlling them. Theoretically speaking, there are two ways in which experiencing emotions by psychopaths can be explained; despite their seemingly contradictory nature, they are in a way complimentary. The first concept, which refers to empathy, assumes that is someone is not aware of his emotional states, then he cannot tune in to emotions of other people, because being open to one's own emotions is the condition of opening up to feelings of other people [4]. The second concept explaining psychopaths' emotions assumes that during socialization psychopaths learnt to experience and focus on emotions related to satisfying their needs, but neglecting the needs of the others [4]. Psychopaths would not differ from other people, because-according to Otley's and Duncan's theory-'the main source of emotions are various events which occur when we pursue a certain goal'.

Meanwhile W. Poznanik thinks that considering the issue of psychopathy in terms of the learning theory, two basic assumptions have to be made: first of all, psychopathy is the result of learning certain special behaviors easily (usually asocial and antisocial), and hence acquiring special social experience; secondly, psychopathy is the result of the inability to learn such behaviors, which are a condition of correct social functioning. In their studies on the learning theory in terms of psychopathy, both Ciarkowska [15] discuss the problem of psychopaths' inability to learn such behaviors, which are the condition of correct social functioning. This assumption is also reflected in the global reference literature $[17,4]$.

In terms of the learning theory, psychopathy is considered to be a syndrome developed by modulation and conditioning like Ullman and Krasner [18], assumes that psychopaths are individuals, who do not exhibit any states of arousal, because their ability to react to stimuli from the external environment was damaged. Another milestone theory is the hypothetical nervous system model, introduced by Gray $[19,20]$ and later developed by D.C. Fowles $[21,22]$. According to this model, Gray's theory [19,20], later developed by Fowles [21-23], is a significant contribution to explaining the processes of extinguishing and postponing reaction with psychopaths. The theory assumes that the nervous system consists of three systems, which interact with each other-the behavioral activation system (BAS), behavioral inhibition system (BIS) and nonspecific arousal system (NAS). It is assumed that both BAS and BIS are responsible for maladaptive (psychopathological) behaviors, nevertheless according to studies conducted by e.g. Ross et al. [24] and Hund et al. [25], the high BAS level is primarily responsible for functional disorders both with psychopaths violating and not violating legal norms. In addition, the authors observed that in case of individuals with psychopathic personality disorders, there is a strong correlation between high BAS and such behaviors, as alcohol and drug addiction, hyperarousal and ADHD.

Meanwhile, such authors as conducted empirical research and drew the same conclusion: there are no differences between psychopaths and not-psychopaths concerning the autonomous skin conductance patterns in response to the presented positive and negative stimuli. Ch. J. Patrick analyzed the experiment he conducted and observed that psychopaths must suffer from selective emotional response deficit. Earlier studies conducted by Land revealed that the arousal reflex indicator is the major indicator of the emotional component, which-in case of psychopaths-is a temperamental deficit related to arousing negative emotions. The theory of somatic markers introduced by A. R. Damasio refers to affective associations, which are triggered by specific stimuli and reactions. According to Damasio, somatic markers develop in brain during the socialization and education process, by associating specific stimuli categories with specific somatic states. Somatic markers make taking decisions easier and regulate behavior, by referring to positive and negative patterns, which are related to specific situations or reactions following them. Damasio assumes that-if an individual avoids a learning process-somatic markers warn him about danger, acting as 'automatic alarm signals'. According to this author's theory, the event and event results anticipation process is unconscious with an average man; however, psychopaths cannot associate punishments and awards with the consequences of their actions, which is why they demonstrate a generalized deficit of forming and applying affective associations. Damasio's theory, although it presents an interesting approach to the etiology of this personality type, neither provides any explanations to psychopaths' interpersonal functioning style, nor explains the specificity of this kind of disorder. For example, other disorders, such as depression or schizophrenia, can also be explained by this theory. According to the author's suggestion, if psychopaths are to undergo therapy, they should be taught to associate stimuli with certain emotional states.

As far as differences in learning among psychopaths and other people are concerned, the role of anticipation is emphasized in the reference literature $[4,17,16]$. The already classical research conducted by R. D. Hare confirmed the hypothesis that psychopaths, in comparison to not-psychopaths, anticipated punishment worse, and hence it was not a factor preventing them from doing certain activities. This theory assumes that the way psychopaths function is related to their learning and motivation deficits. Also further studies conducted by this author revealed that in case of psychopaths neither postponed punishments, nor awards, had any motivating potential. Such individuals prefer such behaviors, which bring immediate gratification and distant punishment.

Studies conducted on psychopaths' learning ability focus currently on three aspects of attention, i.e. attention span, selectivity and divisibility. This approach seems logical, because in order to learn, one has to focus, and potential attention deficits may affect the learning process. The only studies on conditioning in terms of attention span, which were reported in the reference literature, were conducted by Raine and Venables. Although the conducted analyses revealed that psychopaths have no attention deficits, nevertheless some authors suggest that a longer period of time requiring an individual to focus attention, than in the aforementioned experiment (0.67 second), could reveal differences concerning this issue. Kosson and Harpur think that indirect stimuli selection by endogenic mechanisms during a 100-milisecond interval is too short to reveal any differences between psychopaths and not-psychopaths. Attention selectivity includes both rejecting and including certain stimuli in order to enhance attention span. Hare claims that the seeming randomness of psychopaths' reactions, demonstrated by e.g. their feelings to other people or by actions they undertake, is actually the result of an increased attention selectivity level. Psychopaths demonstrate a specific ability to focus stimuli they are interested in and ignore adverse ones. It can be confirmed by research conducted on avoidance, where the punishment was losing money or receiving punishment from a criminal or a women. In other words, material 
values have a high rank in psychopaths' hierarchy of values, which is why they avoid losing money, and even focus on selecting such stimuli, which facilitate receiving financial benefits. The situation is similar in case of persons who inflict penalties, who have a high rank in psychopaths' hierarchy of values, too.

Hare [17] drew attention to the relation between conditioning and psychopaths' value system. Studies conducted by Newman and Kosson proved that enhanced responsiveness to award indicators reduces attention paid by psychopaths to other stimuli. Psychopaths also demonstrate specific attention divisibility deficits in terms of stimuli (visual and auditory) which attract attention. It turned out that these differences refer to auditory stimuli, which is enrooted in neurological theories, and more specifically-with the left hemisphere.

An interesting contemporary kind of the learning theory is the response modulation theory, introduced by J. E Newman. The author and his research team conducted a series of rigorous laboratory experiments, which revealed a kind of psychopathological disinhibition with psychopaths, resulting from passive learning, inhibition of correct responses and weak response modulation. According to Newman's theory, children with the 'psychopathy risk' suffer from information flow deficit, which in turn affects the efficiency of self-regulation. Newman's theory is related to Fowles's [23] and Gray's [20] theory. Although the hypothesis of response modulation with psychopaths is interesting, clinicians and theorists are reluctant to rely on it. They believe that psychopaths' abilities to maintain their position, manipulate, take on various roles and demonstrate personal charm, result simply from their needs, which is why the aforementioned theory cannot be considered as exhaustive. If this theory was to be true, the treatment of psychopathy could be disturbed by information deficits.

Is the concept of a norm useful in the analysis of psychopathic personality disorders?

This question is rhetorical, because it is hard not to include e.g. clinical norms in etiology or diagnostics of the discussed personality type. In addition, as we have already mentioned, psychopathy is featured by breaking or disobeying the binding moral, ethical, legal etc. norms and regulations, which is often reflected by psychopaths' criminal activity. Therefore these individuals have both individual and social disorders.

We would like to draw attention to the theory of psychopaths' leadership skills deficit, which is doubtlessly important to understand the social assessment of psychopaths' behavior. The aforementioned theory was introduced by Gough [2], who assumed that psychopaths are individuals, who suffer from a deficit related to holding the leadership position or being the most important person. Therefore psychopaths are unable to anticipate reactions or understand the significance of other people in their life, which seems to be a characteristic symptom of their illness, and hence their behavior is featured by the lack of empathy and remorse. However, studies conducted on psychopaths' leadership skills are not unequivocal, because even if psychopaths are able to take on the leadership position, then Gough's theory is not exhaustive enough and does not explain this issue clearly enough [26-28]. First of all, this theory does not describe factors responsible for faulty recognition of leadership position by psychopaths clearly enough. Secondly, the core psychopathic features, such as the lack of feeling of guilt, superficial personal charm, manipulation, seeking sensations, cannot be explained by Gough's theory. Referring to the literature of the subject, e.g. to Cleckley's concept, manipulating others, telling others what they would like to hear, the ability to make a positive impression, suggest that psychopaths' erudition is a counterbalance for other deficits [28]. Thirdly, there are no significant relations between personality features and leadership [29]. In the Polish literature K. Dąbrowski [30] categorized psychopaths in terms of their leadership skills, differentiating 'great' and 'small and medium' psychopaths. Cording to this author, great psychopaths cause disasters and destructions, whose consequences are experienced by whole generations throughout many years; the methods they use to achieve their aims are murder, homicide, refining tortures, creating atmosphere of constant threat. According to Dąbrowski, psychopaths like to act in historical dimensions; they most often destroy human and social values, although they sometimes think they actually build it. Small and medium psychopaths act at a smaller scale, committing common crimes and intrigues, using such methods, as tricks and deceptions. They often establish various gangs, juvenile crime groups, frequently act out and seek respect among the so called social outcasts [30]. Summing up Dąbrowski's opinions, it is worth noticing that he describes psychopaths' leadership skills in terms of their faults due to concentrating on subordination of other people and negative symptoms of their submissiveness-violating legal norms. This approach is shared by Cleckley [31], Hare [2], Nussbaum [32] and Kantor [33], who analyzed biographies of such great psychopaths, as Hitler and Stalin, and also small and medium psychopaths committing various crimes, and drew the same conclusions, as Dąbrowski. The authors also pointed out that despite a lot of harm and suffering humanity has experienced from great psychopaths, without them the development of societies would not have been so efficient.

Studies focused on the behavioral aspect of psychopathy conceptualization explore the issue of psychopaths' leadership skills, not related to criminal activity [34]. By presenting leadership features, they try to demonstrate that studies on behavioral functioning of psychopaths are incomplete, because they focus on features of little diagnostic value for psychopaths, and also do not refer to the non-criminal population, which also includes psychopaths. Also Radochoński [35], referring to opinions presented by McCord, McCord and Doren, and Forresta, claims that functional psychopaths, i.e. those who have some ability to function in the social environment seemingly correctly, can be encountered in the following professional groups: shop assistants, police officers, lawyers, sales representatives, politicians, doctors and even priests. Some psychopathic features can help the representatives of these professional groups to achieve their professional objectives. According to Christie and Geis [35], some professional groups include an excessive number of individuals with psychopathic personality. On the other hand, referring to K. Pospiszyl's theory, the concept of Machiavellianism should be introduced when discussing psychopaths' leadership skills. Machiavellianism is associated with manipulating other people in order to achieve values one desires and especially increase one's self-esteem. However, as R. Ł. Drwal has notices, the relation between Machiavellianism and psychopathy is not fully clear, nevertheless on theoretical or descriptive grounds it reflects the way psychopaths function, especially for the fact that when psychopaths establish interpersonal relations, they demand others to be subordinate, and the frequency others surrender to them is amazing. A good example could be descriptions of personalities of famous representatives of various professions, e.g. politics, including Hitler, Stalin or other leaders, who are claimed to have had psychopathic personality.

Summing up the above discourse, we would like to quote a 
Citation: Wojciechowska BP, Bidzan M (2014) The Sense and Pointlessness of the Concept of a Norm in the Analysis of Psychopathic Personality Disorders. J Socialomics 3: 106. doi:10.4172/2167-0358.1000106

statement by Cialdini [36], who said that 'these people act so efficiently due to the way they express what they demand and apply tools of social influence already enrooted in our social environment'.

\section{References}

1. Hare RD (1996) Psychopathy: A clinical construct whose time has come. Criminal Justice and Behavior 23: 25-54.

2. Hare RD (2006) Psychopaty: A clinical of forensic overview. Psychiatric Clinics of North America 29: 709-724.

3. Aleksandrowicz JM (1997) Zaburzenia nerwicowe, zaburzenia osobowości i zachowania dorosłych (według ICD-10). Psychopatologia, diagnostyka, leczenie. Cracow, Collegium Medicum, UJ, Poland.

4. Pastwa-Wojciechowska B (2004) Naruszanie norm prawnych w psychopatii. Analiza kryminologiczno-psychologiczna. Gdańsk, Wydawnictwo Uniwersytetu, Gdańskiego, Poland.

5. Pastwa-Wojciechowska B (2008) Psychopathy and Gender Differences. From Norm to Pathology. In: A. Chybicka, M. Każmierczak (Eds), Appreciating diversity - gender and cultural issues (381-414). Kraków, Oficyna Wydawnicza, Impuls.

6. Jakubik A (1997) Zaburzenia osobowości. Warsaw, Wydawnictwo Lekarskie PZWL.

7. Salekin RT (2002) Psychopathy and therapeutic pessimism. Clinical lore or clinical reality? Clinical Psychology Review 22: 79-112.

8. Hare RD (1991) The Hare Psychopathy Checklist-Revised. Manual, Toronto, Multi-Health Systems.

9. Salekin RT, Rogers R, Sewell K (1997) Construct validity of psychopathy in female offender sample: a multitrait-multimethod evaluation. Journal of Abnormal Psychology 106: 576-585.

10. Schmidt F, McKinnon L, Chattha HK (2006) Concurrent and predictive validity of the Psychopathy Checklist: Youth version across gender and ethnicity. Psychological Assessment 18: 393-401.

11. Nicholls TL, Petrila J (2005) Gender and psychopathy: An overview of importan issues and introduction to the special issue. Behavioral Sciences and the Law 23: 729-741.

12. Mulder RT, Welss JE, Joyce PR, Bushnell JA (1994) Antisocial women. Journa of Personality Disorders 8: 279-287.

13. Lilienfeld SO, VanValkenburg C, Larntz K, Akiskal HS (1986) The relationship of histrionic personality disorder to antisocial personality and somatization disorder. American Journal of Psychiatry 143: 718-722.

14. Frick PJ (1998) Callous-unemotional traits and conduct problems: a two facto model of psychopathy in children. In: D. J. Cooke, A. E. Forth, R. D. Hare (eds), Psychopathy: Theory, research and implications for society (161-188). Dordrecht, Netherlands, Lower Academic Publishing.

15. Ciarkowska W (1979) Wpływ bodźca o znaczeniu emocjonalnym na intensywność zachowania agresywnego osób o zróżnicowanym nasileniu cech psychopatycznych. Studia Socjologiczne 17: 137-153.

16. Hare RD (1998) Psychopathy, affect and behaviour. In: D. Cooke, A. Forth R.D. Hare (Eds.), Psychopathy: Theory, Research and Implications for Society (105--139).Dordrecht: Kluwer.

17. Hare RD (1970) Psychopathy: Theory and Research, Willey, New York, USA.

18. Ullman LP, Krasner L (1969) A psychological approach to abnormal behavior Printice-Hall, USA.
19. Gray JA (1982) Precis of the neuropsychology of anxiety: An inguiry into the function of the septo-hippocampal system. The Behavioral and Brain Sciences 5: 469-534.

20. Gray JA (1987) Perspectives on anxiety and impulsivity: A commentary. Journal of Research in Personality 21: 499-509.

21. Fowles DC (1987) Application of a behavioral theory of motivation to the concepts of anxiety and impulsivity. Journal of Research in Personality 21 417-435.

22. Fowles DC (1988) Psychophysiology and psychopathology: A motivational approach. Psychophysiology 25: 373-391.

23. Fowles DC (1980) The three arousal model: Implications of Gray's two factor learning theory for heart rate, electrodermal activity and psychopathy. Psychophysiology 17: 87-104.

24. Ross SR, Mollo J, Poy R (2007) Gray's model and psychopathy: BIS but not BAS differentiates primary from secondary psychopath in no institutionalized young adults. Personality and Individual Differences 43: 1644-1655.

25. Hund NE, Kimbrel NA, Mitchell JT (2008) High BAS but not low BIS predict externalizing symptoms in adult. Personality and Individual Differences 44 565-575.

26. Widom CS (1976) Interpersonal conflict and cooperation in psychopaths Journal of Abnormal Psychology 85: 330-334.

27. Smith RJ (1978) The psychopath in society. Academic Press, USA.

28. Doren DM (1987) Understanding and treating the psychopath. Wiley, USA.

29. Aronson E, Wilson TD, Akert RM (1997) Psychologia społeczna. Serce i umysł. Poznań, Zysk i S-ka.

30. Dąbrowski K (1985) Zdrowie psychiczne ludzi przeciętnych, wybitnych, o ukształtowanej osobowości oraz problem psychopatii. In: K. Dąbrowski (ed.), Zdrowie psychiczne (165-177). Warsaw, PWN.

31. Cleckley H (1976) The mask of sanity, (5th). St. Louis, Mosby.

32. Nussbaum D (2005) Understanding Psychopathy: Toward a Psychobiologica Synthesis. In: J. Blair, D. Mitchell, K. Blair (eds.). The Psychopath: Emotion and the Brain. Oxford, England: Blackwell Publishing.

33. Kantor M (2006) The psychopathy of everyday life: How antisocial personality disorders affects all of us. Westport, CT, US: Praeger Publisher/Greenwood Publishing Group, USA.

34. Lilienfeld SO, Andrews BP (1996) Development and preliminary validation of a self - report measure of psychopathic personality traits in noncriminal populations. Journal of Personality Assessmennt 66: 488-524.

35. Radochoński M (2000) Osobowość antyspołeczna. Geneza, rozwój i obraz kliniczny. Rzeszów, Wyd. WSP.

36. Cialdini R (1996) Wywieranie wpływu na ludzi. Teoria i praktyka. Gdańsk, GWP.
This article was originally published in a special issue, Clinical \& Health

Psychology handled by Editor(s). Dr. Mariola Bidzan, University of Gdańsk, Canada 